\title{
Role of Arthrocentesis with and without steriod for internal derangement of TMJ
}

\author{
Altaf Hussain Malik \\ Registrar Govt Dental college Srinagar Kashmir INDIA
}

\begin{abstract}
:
Purpose: This study was designed to investigate the efficacy of arthrocentesis and to compare it with arthocentesis with steroid in the treatment of temporomandibular joint (TMJ) internal derangements.

Materials and Methods: 9 males and 11 females aged between 17 to 39 years comprised the study material in the department of Oral \&Maxillofacial surgery at Govt Dental College Srinagar(India). The patients' complaints were limited mouth opening, and TMJ pain. Arthocentesis was performed under all aseptic conditions. Clinical evaluation of the patients was done before the procedure, and 1 week and 6 months after postoperatively. Intensity of TMJ pain and maximal mouth opening were recorded at each follow-up visit.

Results: Both the groups showed significant improvement in mouth opening and reduction in pain scores in the post-operative period however the addition of steroid didn't improve the total outcome of the procedure.

Conclusions:Arthocentesis is simple and safe procedure for the patients of internal derangement with closed lock but addition of steroid doesn't, improve the results.
\end{abstract}

Key words; TMJ; Internal derangement; Arthocentesis; Steriod

\section{Introduction}

Temporomandibular joint disorders (TMDs) are one of the most misdiagnosed and mistreated maladies in the medical practice. TMDs are not life threatening but they may strongly affect the quality of life. Painful temporomandibular joint function disturbs day to day life and body image. These problems sometimes become so significant that they may impair person emotional stability. The term internal derangement was introduced by Hey in 1814 as a general orthopaedic term for alocalised mechanical fault in a joint which later on was used more specifically to describe displacement of the TMJ disc ${ }^{1}$.According to the consensus meeting held bythe International Association of Oral and MaxillofacialSurgeons (IAOMS) in Buenos Aires 1992 regarding TMJ surgery,'Internal derangement is defined as alocalised mechanical fault of the joint which interferes with its smooth action"2. The temporomandibular joint arthrocentesis signifies the lavage of the upper jointcompartment by using physiological saline or Hartmann's solution (ringer lactate) using needles for inflow and outflow ${ }^{3}$. Arthrocenthesis can be performed either under low pressure using an elevated infusion bag or under sufficient pressure by using a syringe ${ }^{1}$. This technique was first introduced at the beginning of the 1990s and derives directly from TMJ arthroscopy, on the basis of the hypothesis that the most effective successful component of TMJ arthroscopy was the simple fact that the patient was submitted to an intervention and not all the complicated manoeuvres intended to recapture the disc, fix the disc, and remove the adherences within the joint using tiny and sophisticated instruments.During the arthrocentesis the jaw can be gently manipulated. Many types of internal joint pathology appear to respond well to arthrocentesis. The most common use appears to be in patients with anterior disk displacement without reduction. Treatment appears to be very effective with results similar to or better than other types of arthroscopic and opensurgical procedure. Nitizan demonstrated that arthrocentesis produced significant improvement in incisal opening and reduction of pain in patients with persistent and severe closed lock ${ }^{1}$.Before the advent of arthrocentesis, the cases not responsive to conservative therapy had to be managed through an arthroscopic procedure, failing which a radical surgical management such as arthrotomy and disc plication would be carried out.Arthroscopy is a highly technique sensitive procedure that requires a dedicated set of fiberoptic endoscopes; it is associated with a high learning curve and many centers, particularly in developing countries, cannot afford the equipment required. In these situations, arthrocentesis offers a solution that is both minimally invasive and leads to a reasonably satisfactory outcome.Arthrocentesis, as originally proposed, used a technique involving the use of two needles that were inserted into the superior joint space at certain points; these points are termed as the McCains points and were marked on a line drawn from the middle of the tragus to the lateral canthus. The entry points were marked along this canthotragal line. The first point corresponding to the glenoid fossa was marked $10 \mathrm{~mm}$ from the midtragus and $2 \mathrm{~mm}$ below the line and the second point corresponding to articular eminence was marked $10 \mathrm{~mm}$ from the first point and 10 $\mathrm{mm}$ below the line. The simple flushing action in the joint may eliminate or decrease biochemical factors contributing to inflammation and pain.Intra-articular corticosteroid are occasionally injected to alleviate the 
intracapsular inflammation.Unfortunately, intra articular corticosteroid injection has an unpredictable prognosis and also cause local side effect on the joint

\section{Materials And Methods}

A total of 20 patients (11 females and 9 males) were evaluated for this study.The age ranged from 17 to 39 yrs. of ag. The study was carried in the departmentof Maxillofacial surgery Govt Dental College Srinagar $(\mathrm{J} \& \mathrm{~K})$.A detailed clinical examination was done and necessary investigations were made. All the patients diagnosed with temporomandibular joint internal derangement closed lock were selected for the study .A written and verbal consent was obtained from the patients for treatement and associated complications, after the treatement outcome were fully explained to them.Visual Analogue Scale was used to score pain and thegrading was done from 1 to 10 where 1 denoted no pain at all and 10 denoted very severe pain. These values were recorded pre-operatively , 1 week after and after 6 months post -operatively. The maximal mouth opening (MMO), was evaluated and recordedpre operatively and post operatively in millimetres $(\mathrm{mm})$. The patients were divided in two groups of 10 each.In one group only arthocentesis was used and in other group arthocentesis was followed by single injection of triamecelone acetoinide $(20 \mathrm{mg})$

.The results were compared pre and post-operatively.

\section{Results}

In our study, mean VAS scores was 6.6 and mean MMO was $23 \mathrm{~mm}$ before treatment. In post treatement phase the mean VAS pain score dropped to 2.7 at 1 week and then to 1.2 at 6 month period,whereas mean mouth opening improved to $34 \mathrm{~mm}$ at 1 week and to mean value of $42.1 \mathrm{~mm}$ at 6 month time period in the steroid group, which indicates significant improvement in patient symptoms and complaints.However the mmo after steroid injection improved from 23.9 to 42.2 (table 2) and pain dropped from 6.7 to 1.11(table4) ,Though the difference between two groups wasn't significant

\section{Discussion}

The technique of TMJ arthrocentesis and lavage with manipulation has gained widespread acceptance,particularly in North America, as a simple and effective technique for the treatment of acute persistent closed lock of the TMJ that is refractory to more conservative measures. The idea of TMJ arthrocentesis and lavage was first borne out of the successful use of TMJ arthroscopy not only as a diagnostic tool, but also as atherapeutic technique resulting in remarkable improvement in pain, jaw opening and function in selected patients through the simple process of lavaging the superior joint space ${ }^{4}$. The hydraulic distension provoked by the under pressure lavage of the upper joint compartment with a large volume of saline has been considered the reason for the positive clinical outcomes in patients with sudden onset closed lock ${ }^{5}$. A single session arthrocentesis was then proven effective also to improve pain and dysfunction in subjects affected by TMJ osteoarthritis, likely due to thorough removal of catabolytes from the joint space ${ }^{6}$.In our study the maximum mouth opening improved from $23 \mathrm{~mm}$ to 42.1 (TABLE1) in arthocentesis group whereas it increased from 23.9 to 42.2 (TABLE2) in arthocentesis with steroid group.The VAS score dropped from 6.6 to 1.2 in arthocentesis group (table3) whereas it dropped from 6.7 to 1.11 in arthocentesis with steroid group(table 4)..Findings did not support the clear superiority of one treatment protocol over the others to achieve pain management in TMJ inflammatory-degenerative joint disease over a short term,viz., 6-month follow-up period.The difference between two treatement groups was clinically insignificant.Findings suggested that neither statistically nor clinically significant differences existed between the treatment groups.This is in conformity with the MANFREDINI et all who compared six different treatement protocols. All protocols were associatedwith positive outcomes, in line with the TMD literature suggesting that improvement is, at least to some extent ${ }^{7}$.Murakami ET al. compared arthrocentesis, arthroscopic surgery, and nonsurgical treatments in TMJ closed lock and found similar values of pain level and jaw dysfunction ${ }^{8}$. They concluded that arthrocentesis,rather than being an alternative to arthroscopic surgery, would be indicated for patients with acute TMJ closed lock refractory to medication and mandibular manipulation. Al-Belasy\& Dolwick ${ }^{9}$ reported in their review study that no medication was used for intra articular injection in four studies, steroid was used in 14 studies and hyaluronic acid was used in 2 studies

Complications are rare in arthrocentesis and are caused more often with arthroscopy ${ }^{10}$.Still, there may be potential complications that may develop with arthrocentesis, such as damage to capsular tissues, discal tissue, increased risk of facial nerve injury, pre auricular hematoma, middle ear injury, and intra-articular instrument breakage. Redundant injury of the capsule by needles can also aggravate inflammation in the joint and increase the incidence of solution extravasation to neighboring tissues when the arthrocentesis is finally performed ${ }^{11-14}$. A rare case of extradural hematoma has also been reported with the conventional technique of arthrocentesis, which could have been because of blind triangulation of the needle. Arthrocentesis and arthroscopy are the primary treatment for patients who fail with conservative method of management of MJ pain, 
restriction and locking. The improvement in mouth opening is irrespective of Wilkes score. There is a clear improvement in pain score based on this intervention and as such this management should be offered routinely ${ }^{15}$.In the absenc of a clear history of trauma, arthrocentesis should be the first line treatment in patient's under 25 years ${ }^{15}$.

The results of this study are in conformity with the other studies which show arthocentesis improves mouth opening and relieves pain but addition of steroid doesn't improve the results.

\section{Conclusion}

TMJ arthrocentesis and lavage with manipulation is a simple, less invasive and less expensive technique with low morbidity that should be considered as an effective and efficient alternative to more invasive surgical procedures in a selected group of patients and is considered a minimally invasive treatment modality, with low morbidity rates and highly effective in the treatment of patients with TMJ closed Lock.

\section{Conflict Of Interest---None}

\section{References}

[1] Adams JC, Hamblen DL. Outline of Orthopedics, $13^{\text {th }}$ ed., London Churchill Livingstone, 2001;135

[2] Nitzan DW, Dolwick MF, Martinez GA .Temporomandibular joint arthrocentesis:a simplified treatment for severe limited mouth opening. J OralMaxillofac Surg. 1991;49:1163- 1167.

[3] Al-Belasy FA, Dolwick MF. Arthrocentesis for the treatment of temporomandibular joint closed lock: a review article. Int J Oral Maxillofac Surg. 2007:18.

[4] Sanders B. Arthroscopic surgery of the temporomandibular joint: Treatment of internal derangement with persistent closed lock. Oral Surg1986;62: 361-364.

[5] Nitzan DW, Samson B, Better H, Long-term outcome of arthrocentesis for sudden-onset, persistent, severe closed lock of the temporomandibular joint. J Oral MaxillofacSurg 1997;55:151-157.

[6] Nitzan DW, Price A. The use of arthrocentesis for the treatment of osteoarthritic temporomandibular joints.J Oral \&Maxillofac Surg. 2001; 59:1154-1159.

[7] Manfredini D, ed. Current concepts ontemporomandibular disorders. Berlin: Quintessence Publishing, 2010:305-318

[8] Murakami KI, Iizuka T, Matsuki M, Ono T.Recapturing the persistent anteriorly displaced disk by mandibular manipulation after pumping and hydraulicpressure to the upper joint cavity of the temporomandibular joint. Cranio 1987;5:17-24

[9] Al-Belasy FA, Dolwick MF. Arthrocentesis for the treatment of temporomandibular joint closed lock: a review article. Int J Oral MaxillofacSurg 2007;36:773-782.

[10] Frost DE, Kendell BD. The use of arthrocentesis for treatment of temporomandibular joint disorders. J Oral Maxillofac Surg. 1999;57:583-587

[11] Carls FR, Engelke W, Locher MC, Sailer HF. Complications following arthroscopy of the temporomandibular joint: analysis covering a 10-years period (451 arthroscopies). J Craniomaxillofac Surg. 1996;24:12-15

[12] McCain JP, Sanders B, Koslin MG, Quinn JD, Peters PB, Indresano AT. Temporomandibular joint arthroscopy: a 6-years multicenter retrospective study of 4831 joints. J Oral Maxillofac Surg. 1992;50:926-930

[13] McCain JP. Complications of TMJ arthroscopy. J Oral Maxillofac Surg. 1988;46:256

[14] McCain JP, de la Rua H. Foreign body retrieval: a complication of TMJ arthroscopy. J Oral Maxillofac Surg. 1989;47:1221-1225.

[15] Sidebottom AJ. Current thinking in temporomandibular joint management.Br J Oral Maxillofac Surg 2009; 47(2):91-4

Table1 :Mouth opening in the arthocentesis only group

\begin{tabular}{|l|l|l|l|}
\hline Patient & $\begin{array}{l}\text { Preoperative } \\
\text { mouth } \\
\text { opening }\end{array}$ & $\begin{array}{l}\text { Post- } \\
\text { operative } \\
\text { mouth } \\
\text { opening(1wk) }\end{array}$ & $\begin{array}{l}\text { Post- } \\
\text { operative } \\
\text { mouth } \\
\text { opening } \\
(6) \text { months) }\end{array}$ \\
\hline 1 & 27 & 35 & 45 \\
\hline 2 & 21 & 33 & 42 \\
\hline 3 & 19 & 30 & 42 \\
\hline 4 & 23 & 34 & 42 \\
\hline 5 & 26 & 35 & 44 \\
\hline 6 & 23 & 33 & 41 \\
\hline 7 & 25 & 37 & 43 \\
\hline 8 & 27 & 35 & 43 \\
\hline 9 & 19 & 32 & 39 \\
\hline 10 & 20 & 36 & 40 \\
\hline Mean & 23 & 34 & 42.1 \\
\hline
\end{tabular}

Table 2:Mouth opening in arthocentesis plus streriod group 


\begin{tabular}{|l|l|l|l|}
\hline Patient & $\begin{array}{l}\text { Pre-op } \\
\text { mmo }\end{array}$ & $\begin{array}{l}\text { Post-op } \\
\text { mmo 1 wk }\end{array}$ & $\begin{array}{l}\text { Post -op } \\
\text { mmo } \\
6 \text { month }\end{array}$ \\
\hline 1 & 25 & 33 & 43 \\
\hline 2 & 24 & 36 & 44 \\
\hline 3 & 27 & 36 & 45 \\
\hline 4 & 24 & 36 & 42 \\
\hline 5 & 18 & 27 & 32 \\
\hline 6 & 19 & 29 & 39 \\
\hline 7 & 26 & 37 & 43 \\
\hline 8 & 23 & 33 & 45 \\
\hline 9 & 27 & 37 & 46 \\
\hline 10 & 26 & 27 & 43 \\
\hline Mean & 23.9 & 33.1 & 42.2 \\
\hline
\end{tabular}

Table 3:Pain in the arthocentesis group

\begin{tabular}{|l|l|l|l|}
\hline Patient & $\begin{array}{l}\text { Pre-op } \\
\text { pain(VAS) }\end{array}$ & $\begin{array}{l}\text { Post-op pain } \\
\text { (VAS) IWK }\end{array}$ & $\begin{array}{l}\text { Post-op pain } \\
\text { months }\end{array}$ \\
\hline 1 & 7 & 3 & 1 \\
\hline 2 & 6 & 4 & 1 \\
\hline 3 & 5 & 2 & 1 \\
\hline 4 & 8 & 3 & 2 \\
\hline 5 & 7 & 3 & 1 \\
\hline 6 & 8 & 4 & 2 \\
\hline 7 & 6 & 2 & 1 \\
\hline 8 & 6 & 2 & 1 \\
\hline 9 & 8 & 3 & 1 \\
\hline 10 & 5 & 1 & 1 \\
\hline Mean & 6.6 & 2.7 & 1.2 \\
\hline
\end{tabular}

Table 4:Pain in arthocentesis plus setriod group

\begin{tabular}{|l|l|l|l|}
\hline Patient & Pain on VAS & $\begin{array}{l}\text { Post-op 1 } \\
\text { wk }\end{array}$ & $\begin{array}{l}\text { Post } \\
\text { op 6 } \\
\text { mnth }\end{array}$ \\
\hline 1 & 7 & 3 & 1 \\
\hline 2 & 8 & 3 & 2 \\
\hline 3 & 6 & 2 & 1 \\
\hline 4 & 5 & 1 & 1 \\
\hline 5 & 7 & 3 & 1 \\
\hline 6 & 8 & 4 & 1 \\
\hline 7 & 5 & 3 & 1 \\
\hline 8 & 6 & 1 & 1 \\
\hline 9 & 8 & 2 & 1 \\
\hline 10 & 7 & 3 & 1 \\
\hline Mean & 6.7 & 2.4 & 1.11 \\
\hline
\end{tabular}

